\title{
LA INTERPRETACIÓN ADAPTATIVA DE LA LEY COMO ATRIBUCIÓN DEL PARLAMENTO Y LA AUTENTICIDAD DE LA SEPARACIÓN DE PODERES
}

\author{
ADAPTIVE INTERPRETATION OF THE LAW: THE CONGRESS' PURVIEW. \\ LEGITIMACY OF THE SEPARATION OF POWERS
}

\author{
Jorge Luis Godenzi Alegre ${ }^{1}$ \\ Universidad de Lima \\ Lima-Perú \\ https://orcid.org/0000-0002-9116-9033 \\ igodenzzi@yahoo.es
}

“El Derecho es la determinación de lo que es justo, no la protección de la casuística de las opiniones".

Aristóteles

\section{RESUMEN}

En este artículo se va a esgrimir algunas ideas en torno a la inacabable doctrina de la separación de poderes - que aún goza no solo a nivel teórico sino práctico de una enorme consideración y seguimiento - con la insustituible y esencial función que cumple el Congreso de la República, sede de la soberanía, cuando actúa ejerciendo su función de órgano modulador e intérprete de la ley.

\section{PALABRAS CLAVE:}

Interpretación, separación de poderes, atribuciones, ley, parlamento

\section{ABSTRACT}

The purpose of this paper is to explain some ideas regarding the infinite academic legal opinions on the separation of powers - which still enjoys enormous consideration and monitoring not only at theoretical but also at practical levels - with the irreplaceable and essential function fulfilled by the Congress of the Republic, the Seat of Sovereignty, when it acts as an oversight body and interpreter of the law..
\end{abstract}

\section{KEYWORDS:}

Interpretation, separation of powers, powers, law, congress.

\section{INTRODUCCIÓN}

Hace más de siglo y medio el abogado francés Maurice Joly (2004) escribió un sugestivo y metafórico texto: "Dialogo en el infierno entre Maquiavelo y Montesquieu". En este libro que ya es todo un clásico se escenifica en el más allá el enfrentamiento de estas dos almas atormentadas. Ambas celebridades abanderando posturas absolutamente divergentes debaten asuntos respecto del tiránico uso de la fuerza contra la utilidad y eficacia del derecho; porfían el uno y el otro en la pugna de imponerle límites al poder o en crearle ciertas fronteras morales a la política.

1 Abogado, con estudios de Maestría y Doctorado, Docente en la Universidad de Lima. Consultor y articulista. 
El oceánico filósofo y jurista francés explica una vigorosa defensa de la separación de poderes como único recurso de garantizar la libertad política de los ciudadanos. El genial político y canciller florentino, por su parte, le demuestra cómo un hombre puede llegar a demoler la más robusta de las democracias y alzarse en tirano mediante el uso fraudulento y cínico de las leyes y de las instituciones. Joly (2004) "Ved cómo los pueblos retornan a la barbarie por el camino de la civilización", le dice Maquiavelo a Montesquieu en los aposentos decorados del infierno.

Son cuestiones medulares sobre las que parece que el tiempo y la geografía no hubiera transcurrido. El sometimiento del poder a la ley es lo que distingue a la civilización de la barbarie. Cuando sucede al contrario y es el poder el que somete a la legislación, la civilización retorna a la barbarie, la jungla en la que la única ley es la voluntad del poder. Y estos son desdichadamente los aspectos gravitantes que de lleno aquejan el comportamiento de la actual organización jurídico política del Estado.

En esta época acosada por el populismo y por dos crisis sucesivas, una económica y otra sanitaria, Maquiavelo lleva cada vez más las de ganar en esa ficticia contienda con el barón de Montesquieu que creía que la mejor forma de prevenir la imposición de la fuerza y el desorden político en el Estado era la de conjurar el despotismo, equilibrando el ejercicio del poder estableciendo un sistema de frenos y contrapesos entre los diversos poderes del estado ante la vislumbre autoritaria, siempre presente, de quienes conciben la separación de poderes como un antojadizo y arcaico límite engorroso a la voluntad arbitraria.

\section{COMPROMISO Y COMPOSICIÓN DEL ESTADO}

El Estado para cumplir su objetivo ha tenido siempre ciertas competencias que la ilustrada doctrina denomina poderes. Estas atribuciones del Estado no pueden ser ejercidas por un órgano único, sobre todo en un Estado complejo, como es el contemporáneo. En el ámbito político tiene que haber cierta división funcional de las competencias para que el Estado así configurado, el llamado estado libre, se caracterice por ser un estado en reposo político. Pues, cada potencial abuso por parte de uno de los poderes tiene como contrapartida una respuesta del otro tendente a neutralizarlo.

Por supuesto que Maquiavelo no lo entendía puesto que fue una época histórica en el que, al príncipe que encarnaba el Estado, se le otorgó una colosal carga política. Hoy, por el contrario, y siguiendo a Montesquieu al Estado se le ha conferido una carga política totalmente desconocida con anterioridad a la clásica división de atribuciones. De ahí que cuando se escribe en la ciencia política o en el derecho constitucional respecto de la separación de poderes, hay que hacer una necesaria e impostergable alusión al barón de Montesquieu. Lo que hay antes de Montesquieu son meros precedentes y lo que hay después de Montesquieu son cuestiones incidentales de los problemas fundamentales que planteó magistralmente el señor de la Brède, don Charles Louis de Secondat, brillante jurista y fulgurante filósofo francés.

\section{DOCTRINA DE MONTESQUIEU}

Es preciso que los poderes estén divididos para mantener un equilibrio entre todos ellos y de esa manera la libertad política pueda manifestarse. Esta es la gran aportación que hace Montesquieu (2017) a la Ciencia política. 
En su obra "El espíritu de las leyes" tiene una parte - el libro XI que titula precisamente "La libertad política en sus relaciones con la Constitución" - dedicada a describir genialmente el fenómeno de la división de poderes.

Comienza diciendo Montesquieu (2017):

Es cierto que en las democracias el pueblo parece hacer lo que quiere, pero la libertad política no consiste en manera alguna en hacer lo que se quiere. En un Estado, es decir, en una sociedad donde hay leyes, la libertad no puede consistir más que en poder hacer lo que se debe querer y a no estar constreñido a hacer lo que no se debe querer

Esto es sumamente significativo, porque los pueblos siempre han creído que la libertad consiste en hacer lo que se quiere, y por eso Montesquieu corrigiéndolos reafirma que eso no es libertad. Los pueblos que pretenden que esto es libertad, están perdidos. Libertad es querer lo que se "debe" querer, apunta con solvencia sapiencial.

De esa guisa, Montesquieu continúa alumbrándonos cuando anuncia: "Hace falta distinguir entre lo que es el espíritu de la independencia y lo que es la libertad. La libertad es el derecho de hacer todo lo que las leyes permiten". Y precisa más: "Si un ciudadano pudiera hacer lo que las leyes prohíben, no existiría más libertad, porque los otros tendrían igualmente el mismo poder". "La democracia y la aristocracia no son en absoluto estados libres por su naturaleza; la libertad política no se encuentra más que en los Gobiernos moderados. Pero ella no se encuentra siempre en los Estados moderados; ella no está más que cuando no se abusa del poder, pero - sigue diciéndonos - es una experiencia eterna que todo hombre que tiene poder está tentado a abusar de él: va hasta que encuentra límites. ¿Quién lo diría? ¡La virtud misma tiene necesidad de límites!”

A resultas de que Montesquieu vivió veinte años en Inglaterra descubrió la Constitución inglesa a los propios ingleses y durante todo ese tiempo estuvo pensando que en todo Estado deben coexistir tres clases de poderes: el poder legislativo, el poder ejecutivo y el poder judicial. Por el primero - el legislativo - el príncipe o el magistrado hace las leyes por un tiempo o para siempre, corrige, interpreta o deroga aquellas que son hechas. Por el segundo - el segundo poder ejecutivo que depende del Derecho de gentes - hace la paz o la guerra, envía o recibe embajadas, establece la seguridad y previene las invasiones. Por el tercero - poder judicial que depende del derecho civil - castiga los crímenes y juzga las diferencias entre los particulares.

Concluye denominando a este último el poder de juzgar y al anterior simplemente poder ejecutivo. Pues bien, dice: "la libertad política de un ciudadano es "esta tranquilidad de espíritu que proviene de la opinión que cada uno tiene de su seguridad"; y para que exista esta libertad hace falta un equilibrio mecánico entre estos tres poderes. Habida cuenta que quien tiene el poder tiende a abusar de él, lo que hace falta es que estos tres poderes se coloquen en esferas totalmente diferentes y de peso específico parecido para que la sociedad viva dentro de un equilibrio estable, debido a que - continúa diciéndonos - si un órgano detenta el legislativo y ejecutivo al mismo tiempo, no hay libertad; si detenta el legislativo o ejecutivo y el judicial, hay mucha menos libertad; pero si concentra los tres poderes en las mismas manos la libertad es nula.

A resultas de ello, lo que hace falta es que en ningún caso se produzca unión en un mismo órgano de estos tres poderes que tienen que estar separados. De esta forma, si un poder tiende a abusar, siempre quedan dos poderes para limar este abuso y reconducirlo a su cauce normal. Lo que no puede ocurrir es que los tres poderes abusen a la vez porque los tres se neutralizan entre 
sí y se ven obligados a mantener un equilibrio que favorecen a la libertad y de ese modo evitar que alguno de esos poderes del Estado se vuelva tiránico y amenace la libertad política, que es el fundamento de las demás libertades.

Por eso, la doctrina de la separación de los poderes ha sido concebida como instrumento insustituible para el respeto de los derechos individuales. Sigue siendo una de las categorías más discutidas y determinantes en la ciencia política. Y sin duda, bajo su inspiración se ha procurado hacer realidad la libertad política y ha proporcionado base organizativa aparentemente irremplazable a todos los modelos constitucionales y que ha servido de piedra angular de la democracia representativa al perfilar los diversos regímenes gubernativos.

De ese jaez es la renombrada doctrina de Montesquieu de la separación de poderes. Como se puede advertir, le da un sentido mecánico de equilibrio político que nadie le había dado antes. Incluso parte de la doctrina ulterior no lo glosa correctamente, porque a partir de entonces se habla siempre de división de poderes cuando Montesquieu no pretendía dividir el poder porque éste es indivisible. Él simplemente establecía que para el ejercicio del poder era conveniente crear esta división de competencias entre estos tres órganos diferenciados y constitutivos del Estado democrático.

\section{VERTIENTE MODERNA DE LA SEPARACIÓN DE PODERES Y FUNCIÓN LEGISLATIVA.}

Desde nuestro particular punto de vista el modelo de pesos y contrapesos continúa representando una estrategia de diseño constitucionalmente deseable porque es consustancial en todo Estado de Derecho, de ahí que debe ser respetada por todos, especialmente por quien representa uno de los poderes del Estado.

El acatamiento a su plena independencia de estos poderes en el Estado es lo que al final de cuentas garantiza el respeto de los derechos fundamentales, los valores indivisibles y universales de la dignidad humana, la libertad, la igualdad, la justicia, el pluralismo político y la solidaridad.

De otro lado, lo que más asegura la persistencia del equilibrio y de la normalidad democrática es que los poderes del Estado funcionen y que se mantengan sometidos únicamente al imperio de la ley, que es la más elevada fuente formal del ordenamiento jurídico - como es el nuestroinexorablemente vinculado al sistema jurídico del civil law o romano-germánico-canónico.

Por ello, resulta incuestionable que la ley, como libérrima expresión de la voluntad soberana de la nación, es vinculante para todos los ciudadanos, sin excepción. por ser el reflejo de la voluntad general. Y, por ende, significa como el acto jurídico acordado por el poder legislativo, sea por iniciativa propia o de otra autoridad competente que va a ser sancionada y promulgada por el ejecutivo, de fijar límites a la actuación de los poderes públicos.

Todos participamos en la elaboración de las leyes a través de nuestros representantes y, por tanto, estamos igualmente sometidos a ella por convicción no discutida. De ahí que la democracia, en el Estado de Derecho, se basa en la supremacía de la ley, indudable resultado de la transacción entre las fuerzas sociales, conjuntamente con el de la separación de poderes, únicos antídotos contra la más inmediata pretensión letal de los populismos de toda laya que una vez que se instalan en el poder por vía democrática se desviven por quebrar la autonomía de los tres poderes del Estado para reducirlos a uno solo: el Ejecutivo. Lacerando gravemente, a través de su control y permanencia en el poder, la línea de flotación del Estado de Derecho y de las libertades políticas 
El prestigioso y polémico jurista alemán Carl Schmitt (1992) dictamina un meritorio punto de vista al sostener que la capital misión de legislar solo le corresponde al Parlamento y las leyes emanadas de esa asamblea han de guardar siempre una conexión con los principios del Estado de Derecho y de la libertad política.

Tras esta aseveración, comprobamos que la fuente formal del ordenamiento jurídico es la ley y su trasunto principista que se discute y se aprueba en el Parlamento y desde el punto de vista constitucional el interés esencial es el de reafirmar el principio de la separación de poderes que es lo que permite determinar con certeza que es la atribución que está sujeta a su competencia, como también el de ejercer la función contralora del Poder Ejecutivo. Por esta lisa y llana razón el poder legislativo tiene primacía en su atribución de interpretar las leyes sobre los otros poderes u órganos constitucionales del Estado.

Como se ha repetido con razón tantas veces, solo el Parlamento Nacional detenta la competencia exclusiva en la producción de la fuente normativa de ley que puede cambiarse o precisarse - esa es la esencia de la democracia- y es la más acabada expresión de nuestras libertades políticas. "Somos siervos de las leyes para poder ser libres", explicaba el excelso tribuno romano Marco Tulio Cicerón, mucho antes.

Por supuesto, nada más defectuoso de quienes aspiran a instaurar una disimetría legal que sobre la base de la grita callejera y los agitadores a comisión moldean una manera de interpretar la ley que deshaga las instituciones jurídico políticas contempladas en la Constitución Política, provocando su acelerado deterioro con la compulsiva afición de construir sistemáticamente argumentos falaces con la finalidad de conservar el poder y estigmatizar al adversario.

La primacía de la ley y la separación de poderes son los únicos garantes del pluralismo y las libertades. Sólo los caudillos renacidos aspiran a dinamitar ese equilibrio, arrogándose atribuciones que no le competen para llevarse por delante a las leyes, valiéndose de interpretaciones espurias en aras de un fin protervo: tomar el poder, cuanto antes y sin restricciones.

Así que aprender a reconocer la aplicación del principio de la separación de poderes como un dique de contención, en favor de la convivencia con la correcta interpretación de la ley, son los genuinos puntales sobre los que se erige el Estado de Derecho.

En efecto, el poder legislativo es el actor más idóneo y calificado para precisar el contenido y alcance de los preceptos que se ubican en la Constitución Política, desarrollándolas y completando su significado.

\section{LA INTERPRETACIÓN DE LA LEY}

Interpretar la ley es fijar o establecer el verdadero sentido y espíritu, conociendo en lo posible el propósito que guio al legislador al dictar la ley. Modernamente la interpretación de la ley tiene un sentido más amplio y eficaz. Entendiéndose como la fijación de su sentido exacto. Consignar la determinación de sus verdaderos alcances y sobre todo la conciliación del contenido de la norma con la realidad social vigente a la luz de los valores, principios y reglas del ordenamiento legal en su conjunto.

Nosotros creemos que lo más seguro es atenerse a la letra; que no debemos ampliarla o restringirla, sino cuando de ello resulten evidentes absurdos y contradicciones; y que todo 
otro sistema de interpretación abre ancha puerta a la arbitrariedad, y destruye el imperio de la ley. (Ducci, 2006, p.96)

Este párrafo explica la razón de incorporar las normas que regulan la interpretación y qué es lo que está más cercano a la idea de buscar la voluntad del legislador. Se puede constatar cómo en las normas que interpretan el precepto constitucional se abandona el criterio tanto el de la literalidad como el de la presunta voluntad del legislador a fin de establecer consciente o intuitivamente como base de la hermenéutica, la objetividad del sentido de la ley.

La interpretación auténtica o legislativa es aquella que se realiza por medio de otra ley; es decir que el sentido de una ley dada, inclusive aquellas que tengan rango constitucional, debe ser esclarecido en casos sumamente necesarios por el mismo órgano legislador. No se trata en este tipo de interpretación, de formular nuevas normas, ni de expresar otra voluntad sino de reiterar la del legislador que ya fue manifestada en la ley que interpreta. Por eso es que se considera que la ley interpretativa emanada del parlamento debe formar un solo cuerpo con la ley interpretada.

En consecuencia, la interpretación auténtica mediante una nueva ley, debe limitarse solamente a declarar el sentido de otra ley precedente que consiste en que los mandatos constitucionales son susceptibles de desarrollo infinito, tanto por el juez como por el legislador, y ambos pueden llegar a soluciones divergentes (García, 1984).

Y ello puede ocurrir cuando algunos de sus preceptos según Hart (2012) revelan cierta ambigüedad o presentan una "textura abierta o se encuentran específicamente en la zona de penumbra" (p.46). y que han sido burda e interesadamente desfiguradas. En todas estas circunstancias se precisa de una tarea interpretativa.

Y en ese afán existen en la doctrina un conjunto de criterios hermenéuticos: gramaticales o literales, sistemáticos, históricos, sociológicos y teleológicos. Y de todos esos criterios habría que tomar en cuenta el sociológico, vale decir la realidad social imperante del tiempo en que han de ser aplicadas, en virtud del cual es posible adaptar los preceptos jurídicos a circunstancias sociales nuevas surgidas con posterioridad a la formulación de aquellos preceptos.

En definitiva, estamos ante lo que se ha venido a denominar interpretación progresiva o evolutiva de la ley a través de la cual se consigue que las leyes mantengan un inmejorable acompasamiento entre el texto de la norma, que permanece inalterado, y la nueva realidad del momento en que la ley ha de ser aplicada, que, por eso mismo, requiere otra interpretación.

La aplicación de la ley constituye en sí misma un método de lectura de la realidad jurídica, no sólo de los textos legales sino también de los hechos que los unen, hechos que el jurista sabe leer en términos jurídicos, es decir, interpretar y conectar entre sí. No basta con conocer el derecho, se necesita aplicarlo, o, lo que es igual, conocer la realidad a través de él. (Frosini, 2019 p.65).

En definitiva, se alude a los dos modelos de interpretación que Perelman (1984) ha diferenciado: interpretación estática o teoría subjetiva de la interpretación, donde la voluntad del legislador (voluntas legislatoris) se convierte en el objetivo principal del intérprete, y la interpretación dinámica o teoría objetiva de la interpretación, donde el objetivo principal del intérprete es la voluntad de la ley (voluntas legis). 
Ricardo Guastini (1990) al exponer las técnicas interpretativas explica la denominada interpretación evolutiva, que es aquella en virtud de la cual la interpretación de la ley debe cambiar cuando cambien las circunstancias en las que la ley debe ser aplicada. Es preciso en estos casos atender no a la voluntad del legislador que dictó la norma, sino a la "naturaleza de las cosas". Es decir, al cambiar las circunstancias históricas (políticas, sociales, culturales) en las que una ley debe ser aplicada, debe cambiar, igualmente el modo de interpretarla.

Se atribuye así a un texto normativo un significado nuevo, distinto, del que históricamente había tenido. La interpretación evolutiva, afirma Guastini, tiende a adaptar viejas o relativamente viejas leyes a situaciones nuevas no previstas por el legislador histórico. Especialmente, hace alusión Guastini a este tipo de técnica interpretativa cuando alude a la interpretación constitucional.

En efecto, se hace eco de una doctrina muy difundida acerca de la cual a la Constitución le debe ser aplicada una interpretación llamada evolutiva. Al texto constitucional se le ha de atribuir un significado diverso del histórico, diverso del que tenía en el momento de su creación, con la finalidad de adaptar el contenido normativo a las cambiantes exigencias políticas o sociales.

Señala Guastini (1990) que esta doctrina resulta tanto más persuasiva cuando el documento constitucional de que se trata es más permanente en el tiempo. Argumenta, entre otros motivos que la Constitución como "el contrato social" que funda una comunidad incorpora un sistema de valores que requieren una interpretación finalista de la misma; que si hay dos interpretaciones posibles de un precepto, una ajustada a la Constitución y otra no, debe optarse por la primera y en cuanto tal debe ajustarse a los valores ético-políticos dominantes en el seno de la comunidad, por lo que la interpretación de la Constitución debe cambiar cada vez que cambien los valores socialmente difundidos. Al poder legislativo, intérprete privilegiado de la Constitución, le incumbe la misión de acompasar el texto constitucional a las necesidades.

\section{CERTEZA EN LA INTERPRETACIÓN DE LA LEY.}

La seguridad jurídica está constituida por la certeza de que habrá estabilidad normativa y que instituciones como la separación de poderes con la recta interpretación de las leyes no debe ser suplantadas por el palanqueo político, las habilidades doctrinarias y la capacidad contenciosa del ejecutivo.

Esta es una de las tantas razones por la cual el parlamento nacional puede utilizar válidamente el criterio de la interpretación evolutiva si se trata de sostener y darle viabilidad a la Constitución Política, adaptando sus propios preceptos a las realidades de la vida moderna a fin de asegurar su propia relevancia y constitucionalidad.

Todo lo cual obliga a preguntarse si el criterio evolutivo, que no figura en nuestra Carta Magna, puede utilizarse válidamente como criterio interpretativo.

Dicen los sabios como Montesquieu que, en tiempos de revueltas, como estos que corren, aparecen grupos de avispados penenes que pregonan el para qué dividir el poder si gobierna el pueblo. Para qué limitar el poder si gobiernan ellos. Ya no es necesario que el poder frene al poder. Qué sentido tiene frenar al pueblo.

Entonces con esa línea de pensamiento antidemócratico el camino hacia el absolutismo y el totalitarismo queda abierto. Es decir, se habrá impuesto cínica e ignaramente la razón de Estado de Maquiavelo (el 
fin justifica los medios) y con ello la insoportable levedad de la política de consignas contra la doctrina de la separación de poderes y las leyes adaptativas, vía interpretación evolutiva, que el Congreso de la República puede y debería constitucionalmente generar para salvaguardar la República.

Finalmente, nada nos impide publicar nuestra lealtad constitucional a la separación de poderes, así como a la interpretación adaptativa de las leyes, que son valores que impulsan a seguir adelante por el buen camino que nos traza el Derecho. "Feliz aquél que alberga pura lealtad en su pecho; nunca le pesa sacrificio alguno”, decía genialmente el otro clásico, el alemán ( Goethe 2015 p.44).

\section{CONCLUSIONES}

De lo expuesto en el presente artículo en torno a la interpretación adaptativa de la ley como atribución del parlamento nacional y la autenticidad de la separación de poderes, podríamos arribar a las siguientes conclusiones:

1. Se destaca la vigencia de las ideas de Montesquieu en una preocupación - que es la de nosotros - de cómo articular el poder y la libertad, aceptando que la naturaleza humana tiende indefectible al abuso y que, como el propio Montesquieu lo manifestara, hasta la virtud necesita límites. Él pensaba a diferencia de Maquiavelo que la política no es un fin, es un medio para los ciudadanos, protege el espacio común de igualdad ante la ley. Y la separación de poderes, tal como lo formulara, debe estar orientado a evitar una concentración del poder que ocasione su abuso o su ejercicio arbitrario, con la consiguiente lesión para la libertad política y seguridad de los ciudadanos.

2. La doctrina de la separación de poderes de Montesquieu, que debería ser indisoluble en toda democracia, no es la división de los poderes. No se puede dividir lo que es invisible, apunta el filósofo francés. El poder que es una abstracción y que es único, no se descompone en el Estado. Lo que establece es que cada poder respete, acometa y se obliguen entre ellos a cumplir con las atribuciones que les asigna el poder constituyente, vale decir lo que imperativamente dictamina la Constitución Política del Estado.

3. La fuente principalísima de nuestro ordenamiento jurídico es la ley y por lo mismo requiere de consistencia, claridad y sentido para otorgar certeza a la ciudadanía y a los propios poderes del Estado.

4. La Constitución Política del Perú preceptúa en el artículo $102^{\circ}$ inciso $1^{\circ}$ que son atribuciones del Congreso de la República interpretar, modificar o derogar las leyes. Por lo tanto, es atribución del Estado a través del poder legislativo interpretar las leyes. (A maiori ad minus, es decir, si la ley autoriza lo más, implícitamente permite lo menos).

5. Es un hecho, que la Constitución Política del Perú no le ha otorgado la prominente atribución al Tribunal Constitucional de erigirse como el supremo intérprete de la Constitución. Sin embargo, aplicando la "ley de desarrollo constitucional" al que alude la Octava Disposición Final y Transitoria de la Constitución que, dicho sea de paso, solo se aplica solo para asuntos de prioridad exclusiva, este órgano político y jurígeno del Tribunal Constitucional, aplicando la interpretación extensiva le concedieron esa "atribución" extraordinaria, plasmándolo en su Ley Orgánica y en su Código Procesal Constitucional. Es una manifiesta cobertura jurídica que nuestra Carta Magna no le ha otorgado. (A minori ad maius, es decir, si la ley prohíbe lo menos, con mayor razón prohíbe lo más). 


\section{REFERENCIAS}

- Ducci C, (2006). Interpretación Jurídica. Editorial Jurídica de Chile.

- Frosini, V (2019). La letra y el espíritu de la ley.Ediciones Olejnik.

- García A. (1984). La interpretación de la Constitución. Centro de Estudios Constitucionales.

- Goethe, J (2015). La vida como obra de arte. Edimat.

- Guastini, R. (1999). Estudios sobre la interpretación jurídica. UNAM

- Hart, H.L.A., (2012). El concepto de Derecho. Universidad de Oxford.

- Joly,M (2004). Dialogo en el infierno entre Maquiavelo y Montesquieu. Colofón

- Montesquieu, Ch (2017.) El espíritu de las Leyes. Createspace Independent publishing platform.

- Perelman, Ch. (1984). Lo razonable y lo irrazonable en derecho. Librairie Générale de Droit et de Jurisprudence.

- Schmitt, C. (1992). Teoría de la Constitución. Alianza. Editorial.

Fecha de recepción : 29 de octubre de 2021

Fecha de aceptación : 19 de noviembre de 2021 